
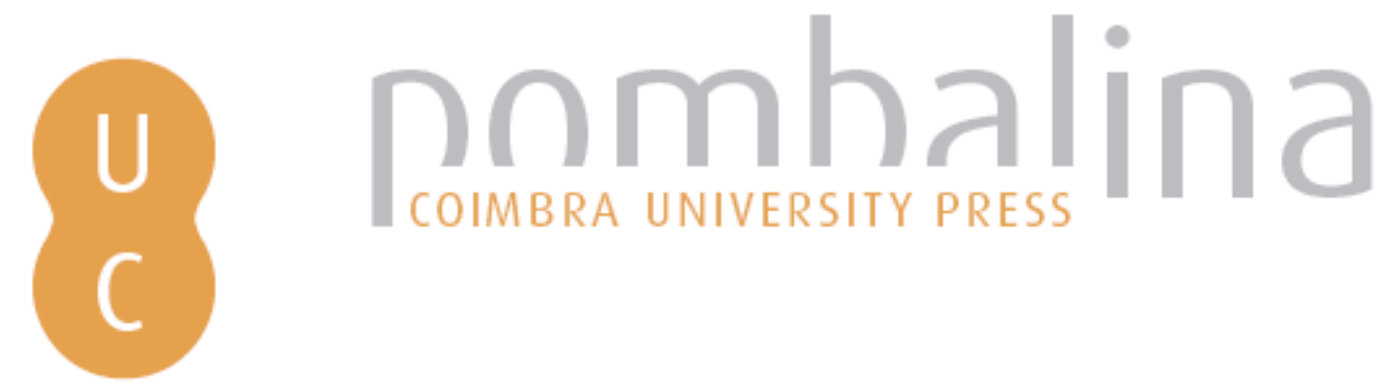

\title{
O lado errado do Marenostro: o elemento mouro como símbolo de alteridade e barbárie em Um deus passeando pela brisa da tarde
}

\author{
Autor(es): $\quad$ Alves, Carla Carvalho \\ Publicado por: Imprensa da Universidade de Coimbra \\ URL \\ persistente: URI:http://hdl.handle.net/10316.2/37032 \\ DOI: $\quad$ DOI:http://dx.doi.org/10.14195/978-989-26-0548-7_12 \\ Accessed : $\quad$ 26-Apr-2023 01:53:01
}

A navegação consulta e descarregamento dos títulos inseridos nas Bibliotecas Digitais UC Digitalis, UC Pombalina e UC Impactum, pressupõem a aceitação plena e sem reservas dos Termos e Condições de Uso destas Bibliotecas Digitais, disponíveis em https://digitalis.uc.pt/pt-pt/termos.

Conforme exposto nos referidos Termos e Condições de Uso, o descarregamento de títulos de acesso restrito requer uma licença válida de autorização devendo o utilizador aceder ao(s) documento(s) a partir de um endereço de IP da instituição detentora da supramencionada licença.

Ao utilizador é apenas permitido o descarregamento para uso pessoal, pelo que o emprego do(s) título(s) descarregado(s) para outro fim, designadamente comercial, carece de autorização do respetivo autor ou editor da obra.

Na medida em que todas as obras da UC Digitalis se encontram protegidas pelo Código do Direito de Autor e Direitos Conexos e demais legislação aplicável, toda a cópia, parcial ou total, deste documento, nos casos em que é legalmente admitida, deverá conter ou fazer-se acompanhar por este aviso.

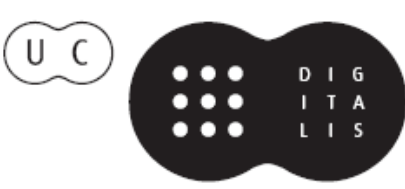


do Tempo e da História

- Mário de Carvalho e a reflexáo metaficcional sobre o futuro do romance - Sátiva e o cepticismo: configuração de personagens em Mário de Carvalho - Escrever tem arte e tem segredos... Era bom que trocássemos umas ideias sobre o assunto - O processo criativo em Era bom que trocássemos umas ideias sobre o assunto - Intertextualidade e metaficção em Fantasia para dois Coronéis e uma Piscina, de Mário de Carvalho - Trimalquiāo, os coronéis e a piscina: retrato impiedoso de um pais em crise $\bullet A$ Paixão do Conde de Fróis: paródia e subversão • "Como dizia o outro": a presença dos Clássicos em Mário de Carvalho - Cultura Clássica em Um

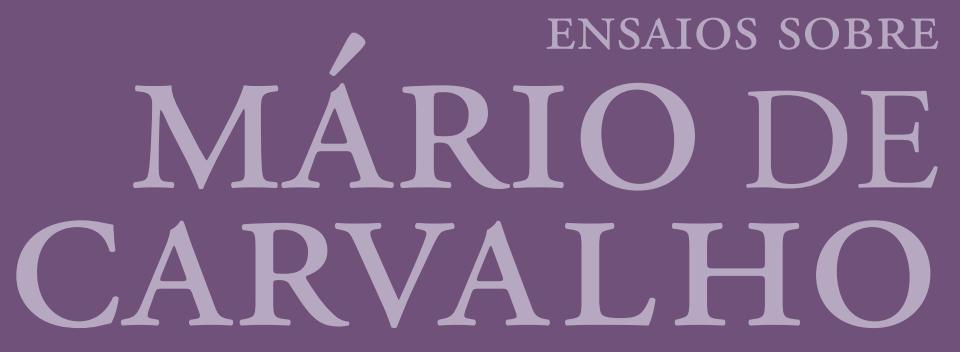

Maria de Fátima Silva Tereza Virgínia Ribeiro Barbosa COORD. IMPRENSA DA UNIVERSIDADE DE COIMBRA COIMBRA UNIVERSITY PRESS

elemento mouro como simbolo de alteridade $e$ barbárie em Um deus passeando pela brisa da 


\title{
O lado errado do Marenostro: o elemento mouro como símbolo de alteridade e barbárie em \\ Um deus passeando pela brisa da tarde
}

\author{
Carla Carvalho Alves \\ Pesquisadora de pós-doutorado da USP \\ Bolsista da FAPESP
}


(Página deixada propositadamente em branco) 
O título desse artigo provém de um diálogo contido na obra de Mário de Carvalho, Um deus passeando pela brisa da tarde, no qual se discute a invasáo dos mouros a uma província da Lusitânia. Um dos personagens, ao refletir sobre a origem desses invasores, faz a seguinte colocação: "Tudo a mesma gente: púnicos, mouros... Farinha do mesmo saco. O lado errado do Marenostro." (Carvalho, 1997: 23).

O referido romance de Mário de Carvalho foi publicado pela primeira vez em 1994, sendo contemplado, no ano seguinte, com o Grande Prêmio da Associação Portuguesa de Escritores. Observa-se nessa obra a abordagem histórica, concernente ao II século da Era Cristá, em uma província da Lusitânia, de nome Tarcisis. O caráter histórico da narrativa, entretanto, fica comprometido desde o início do texto, quando se lê uma advertência sobre a inexistência histórica de Tarcisis e a consequente inadequação de Um deus passeando pela brisa da tarde à categoria de romance histórico.

O contexto inicial da obra de Carvalho retrata a condição de desterrado em que se encontrava o duúnviro, Lúcio, no momento em que decide escrever um livro sobre os acontecimentos ocorridos durante sua segunda magistratura. O elemento motivador para essa iniciativa, também aí contemplado, origina-se da visita de Proserpino, outro magistrado de Tarcisis, à villa na qual se refugiaram Lúcio e sua esposa Mara. A presença do antigo colega desperta no anfitrião lembranças de acontecimentos dolorosos, por ele vivenciados. Mesmo que Proserpino, em atitude inesperada, não tivesse mencionado nenhum fato pretérito que pudesse causar constrangimentos, sua simples presença parece ter significado para Lúcio uma referência metonímica representativa de todo o seu passado. A emergência incômoda de recordaçóes ainda pouco remotas para o protagonista ocasiona, dessa forma, a necessidade de sua reconstituição memorial, através da escrita, como se observa nas seguintes palavras de Lúcio: "Pode ser que, escrevendo, se me apazigue o espírito, com manifesta utilidade para mim." (Carvalho, 1997: 26)

Situaçóes relativas aos âmbitos público e privado, vivenciadas por Lúcio, confluiráo ocasionando o já mencionado desterro final do personagem. Os principais problemas políticos enfrentados por ele referem-se à presença de uma nova seita religiosa em Tarcisis - o cristianismo - e à possibilidade de um ataque mouro à cidade. Paralelamente a estas questóes de ordem pública, Lúcio expóe-se a um conflito pessoal ainda mais intenso: a atração inevitável sentida por Iunia Cantaber, representante fervorosa do cristianismo, religião ainda incipiente na Lusitânia, causadora de escândalo e revolta aos cidadãos de sua cidade. 
Acompanha-se, então, ao longo da narrativa, o encaminhar-se do protagonista para um completo isolamento em relação ao povo de Tarcisis, assim como aos outros magistrados e, até mesmo, ao poder supremo de Roma, representado por Marco Aurélio Antonino. Também contribuem para o insucesso de Lúcio seus valores e gostos pessoais, bastante afinados com a cultura literária grega e latina, e totalmente dissonantes em relação aos jogos e espetáculos violentos que entretinham a plebe.

Quando, finalmente, ocorre o cerco dos mouros à Tarcisis, a imagem pública de Lúcio já está bastante desgastada, e quem se configura como o grande herói da situação, salvando inclusive a vida do duúnviro, é seu inimigo Rufo Cardílio. Com a partida dos chamados povos bárbaros, retomam-se as atividades rotineiras da cidade, reorganizando-se um evento que havia sido suspenso devido à situação de instabilidade enfrentada: o julgamento dos cristáos. As conjunturas fazem com que o protagonista seja obrigado a proceder ao julgamento dos religiosos, e a declarar a pena máxima a Iunia Cantaber, o que provavelmente resultaria em sua morte. Segue-se, ainda, o último e fatal abalo à vida pública de Lúcio: a condenação ao exílio.

É a partir dessa ambientação tão singular, e já em si mesma conflituosa, que Lúcio Valério Quíncio, exilado em uma propriedade rural, elabora sua narrativa memorial. Através de sua história, ele vai trançando uma rede de questóes políticas, religiosas e éticas, seguindo sempre uma lógica opositora entre a aparente sensaçáo coletiva de segurança e estabilidade, gerada pela crença em um Império indestrutível, e os reais conflitos e angústias individuais daqueles que, devido às suas insatisfaçóes pessoais, desafiam o que ele chama de "esta mediocridade dourada" (Carvalho, 1997: 13). Os eventos, assim dispostos, pretendem apenas reapresentar a sequência cronológica da narrativa de Um deus passeando pela brisa da tarde, realçando algumas questôes factuais que se articulam, ocasionando o desafortunado destino cumprido por Lúcio Quíncio. A sutil complexidade do romance constitui-se, entretanto, nos interstícios dos fatos aí retratados.

O próprio período histórico abordado, segundo século da Era Cristã, apresenta, a partir de uma perspectiva arguta, presente à elaboração narrativa, uma amostragem interessante de padróes políticos, religiosos, filosóficos e sociais. A imbricação entre paganismo greco-romano, cristianismo, tragicidade e estoicismo, coloca em pauta complexas dicotomias como: indivíduo e coletividade, o homem e a ordem, nómos (lei) e physis (natureza), civilização e barbárie. Embora em todas essas relaçóes possamos perceber afinidades com o tema aqui abordado, interessa-nos, mais especificamente, o último 
par, aparentemente antitético, mas a respeito do qual tentaremos ressaltar a existência de uma relação associativa e inclusiva. Ou seja, o que normalmente é entendido como uma bipolaridade, civilização e barbárie, parece apresentar-se, a partir da presença do elemento mouro em Um deus passeando pela brisa da tarde, como uma situação de interdependência: a barbárie como estrutura intrínseca e necessária ao processo civilizatório romano.

Acompanha-se, no enunciado do romance como um todo, a generalização no tratamento do outro, ou daqueles que não pertencem ao Império Romano: os chamados povos bárbaros. Essa redução da diversidade de alteridades a uma denominação única - bárbaros - pode ser identificada com aquela concepção, proveniente da antiguidade grega, que considerava bárbaros os povos que não falassem grego. Apreende-se, então, ao longo da narrativa que, para os habitantes da Lusitânia, a atribuição da barbárie aos invasores mouros origina-se dos parâmetros civilizacionais atribuídos à romanidade, os quais reduzem a diversidade dos povos não romanos a uma massa uniforme, considerada apenas pela sua diferença em relaçáo ao Império.

Coloca-se, de fato, no romance de Mário de Carvalho uma contraposição entre os mouros invasores e os lusitanos romanos, na qual se expressa uma concepção bastante cristalizada daqueles povos, revelada, de modo mais contundente, através da expressão, anteriormente mencionada: "O lado errado do Marenostro." (Carvalho, 1997: 23). Mas, esse tipo de generalização, feita por um dos personagens, Proserpino, e representativa, também, do pensamento geral dos cidadãos de Tarcisis, mostra-se frágil e imprecisa quando comparada a algumas reflexóes elaboradas pelo protagonista, Lúcio Valério Quíncio, ao contemplar a descrição do ataque mouro à regiáo da Lusitânia.

Se podemos, pois, acompanhar, ao longo do romance, uma interessante discussão relativa à identificação do mouro como bárbaro, devido à divergência entre sua (falta de) cultura e a cultura romana, da qual faz parte o narrador, há, ainda, outra questão, menos explícita, que acaba, também, sendo sugerida no enunciado da obra: a similaridade existente entre as práticas romanas e os rituais bárbaros. Em diversos momentos, a trama conduz a reflexóes sobre uma "cultura bárbara" amplamente difundida e aceita no Império Romano, em suas arenas de gladiadores, no sacrifício dos condenados jogados aos cáes, enfim, nos espetáculos sangrentos que entretinham o povo.

Mas, para além da barbárie associada ao invasor mouro, apresentado como uma alteridade inapreensível e, ainda, daquele contexto, vinculado às 
práticas violentas exercidas no interior do Império Romano, emerge, também, do discurso de Lúcio, outra expressão referente ao âmbito da barbárie. Identificamos, pois, como uma inusitada "invasão bárbara", o sentimento passional de Lúcio por Iunia Cantaber, sendo esta expressão ainda mais devastadora, pois chega a alcançar e desestruturar, até mesmo, as defesas pessoais do protagonista, entâo sustentadas pela racionalidade e moderação estóicas e pelo sentido de civilidade romana.

Apresentaremos, a seguir, mais detalhadamente, cada uma das três referidas elaboraçôes acerca da temática da barbárie, motivadas pela presença moura no discurso memorial de Lúcio Valério Quíncio.

\section{1 - O mouro como representação da alteridade}

O capítulo IX da obra de Mário de Carvalho inicia-se de forma um tanto abrupta com a seguinte frase: "É isto um mouro?" (Carvalho, 1997: 141). A inversão do sentido natural da frase, com o deslocamento do verbo para o seu início, a utilizaçáo do pronome isto, determinando a reificação do mouro, e, ainda, o tom interrogativo da sentença remetem, sem dúvida, ao título da obra de Primo Levi, É isto um homem?. A narrativa de Levi contempla, entretanto, a experiência, em campos de concentraçáo, vivida pelo autor, um judeu italiano, durante a Segunda Guerra mundial. Mas, há um ponto bem evidente, entre outras questôes mais sutis, que discutiremos adiante, que parece indicar, de fato, a relação entre as obras. Como se pode acompanhar abaixo, a seguinte citação apresenta uma colocação bastante cruel sobre o chamado prisioneiro "muçulmano":

No Campo, porém, acontece o contrário. Aqui a luta pela sobrevivência é sem remissão, porque cada qual está só, desesperadamente, cruelmente só. Se um Null Achtzehn vacila, não encontrará quem lhe dê ajuda, e sim quem o derrube de uma vez, porque ninguém tem interesse em que um "muçulmano" a mais se arraste a cada dia até o trabalho; (Levi, 1988: 89)

Em nota de rodapé, o autor explica que o termo alemão muselmann, cujo significado é muçulmano, era usado pelos veteranos do campo de concentração para designar os prisioneiros mais fracos. A partir daí, muitas outras vezes, o narrador utiliza esse mesmo vocábulo para se referir aos presos destituídos de qualquer proteção e ineptos para a sobrevivência no 
Campo. É nesse contexto que percebemos a interseção mais óbvia entre a narrativa de Primo Levi e o romance de Mário de Carvalho. Se na obra de Levi, o termo "muçulmano", totalmente desvinculado de seu significado dicionarizado, referente aos seguidores de Maomé, funciona como designação pejorativa daqueles que ocupavam os lugares mais baixos na peculiar hierarquia de Auschwitz, em Um deus passeando pela brisa da tarde, como já foi comentado, parece decorrer de uma postura arbitrária a identificação dos mouros como bárbaros. Como dissemos, no período histórico aí retratado, não existia ainda a religião muçulmana, e o cristianismo era apenas incipiente, mas, mesmo assim, sem a usual justificativa religiosa, o elemento mouro é eleito representante da alteridade bárbara, que ameaça a estabilidade da Lusitânia romana.

É claro que, diferentemente do completo deslocamento significativo do termo "muçulmano", em É isto um homem?, no romance de Mário de Carvalho, a denominação de mouros, dada aos invasores, está atrelada, de fato, à origem étnica desses povos. O que tentamos ressaltar, no entanto, é que em ambos os casos a contemplaçáo do mouro e do muçulmano decorre de uma escolha deliberada desses elementos como representativos de uma alteridade impessoal, objetivada, reificada.

$\mathrm{Na}$ narrativa de Um deus passeando pela brisa da tarde, os invasores poderiam ser quaisquer outros estrangeiros, como os púnicos, também referenciados na obra, mas é apenas o elemento mouro, possivelmente devido ao seu papel significativo, no posterior desenrolar histórico da cultura portuguesa, que assume esse lugar. Já o texto de Levi reflete a realidade do campo de extermínio nazista, onde um linguajar próprio é constituído, juntamente com um conjunto de padróes sociais específicos desse microcosmo. E, embora a narrativa não apresente explicaçóes relativas a essa inusitada denominação, que identifica os judeus com terminologia designativa de seus inimigos históricos, essa atitude expressa, sem dúvida, uma preconceituosa ironia, pois são justamente os prisioneiros, em situação mais precária, que são designados, como "muçulmanos".

O seguinte excerto apresenta, de maneira impressionante, o esvaziamento de qualquer vestígio de humanidade nos chamados "muçulmanos":

A sua vida é curta, mas seu número é imenso; são eles, os "muçulmanos", os submersos, são eles a força do Campo: a multidão anônima, continuamente renovada e sempre igual, dos não-homens que marcham e se esforçam em silêncio; já se apagou neles a centelha divina, já estão tão vazios, que nem podem realmente sofrer. Hesita-se em 
chamá-los vivos; hesita-se em chamar "morte” à sua morte, que eles já nem temem, porque estão esgotados demais para poder compreendê-la. (Levi, 1988: 91)

Aqui, o narrador que vivencia e também observa atentamente a barbárie imposta no Campo de Concentração, elabora, entáo, o que nos parece ser a consequência mais brutal da situação: a formação de uma "multidão de náo-homens", que sequer pode sofrer, pois esse sentimento implica um traço da interioridade humana que eles já não possuem. Uma diversificada gama de violência, determinante da exaustão física, emocional e psicológica, justificaria, nesse relato, a alienação e desumanização de toda essa coletividade "muçulmana".

Prosseguindo, então, a analogia, anteriormente sugerida, entre os "muçulmanos" de Auschwitz e os mouros invasores da Lusitânia, estabeleceremos um paralelo, entre a citação acima, referente à multidão desumanizada descrita por Levi, e os seguintes trechos do romance de Mário de Carvalho:

Nada que se parecesse com uma ordem de batalha ou uma legiáo em marcha. Aparentavam antes uma revoada de insectos, amolecida pelo calor, perdidas as asas, dispersando-se cautelosamente na altura em que se lhes arrasa o ninho. Arrastavam-se indivíduos e grupos dispersos, uns carregando fardos, outros eriçados de armas rudimentares, outros trazendo o seu jumento, alguns a cavalo, a grande maioria a pé, pouquíssimos de carro. Não havia ali vanguarda nem retaguarda, nem vélites nem impedimenta. Era uma massa, dispersa, à toa, pela charneca fora. E mostravam-se tấo escuros e pobres os seus trajos que pareciam nascidos da terra e comungar da mesma constituição dos matos e tojos secos que pisavam. (Carvalho, 1997: 221)

Este excerto é parte do relato feito por Lúcio, quando vê, pela primeira vez, os mouros aproximando-se das muralhas da cidade. Nota-se que a pobreza e desorganizaçáo dos invasores, comparativamente às legiôes romanas, foi o que mais lhe chamou a atenção, comparando-os, por isso, a um agrupamento de insetos ou a uma massa disforme constituída por elementos telúricos. De forma análoga, o informante Airhan parece visualizar os mouros de um modo táo generalizante e superficial que, em sua descrição sobre esses povos, chega a compará-los às nuvens de gafanhotos: 
[...] Airhan comparava-os às nuvens de gafanhotos que em anos de praga fazem o mesmo percurso por sobre as ondas, revoada após revoada. E assim como esses animais depredam e deixam rasos de verdura os campos, assim estes invasores vinham para talar, por círculos mais e mais vastos, as fazendas e as vidas em redor. $\mathrm{E}$ as suas mandíbulas eram rudes armas de pedra e osso e o sinal da sua passagem a devastação dos fogos. (Carvalho, 1997: 55)

Nas duas citaçóes acima, a desumanização do mouro constitui-se através dos discursos de Lúcio e Airhan, ao valerem-se de analogias feitas aos insetos para descreverem esse povo. Já o seguinte fragmento, apresenta não mais o discurso, mas a própria ação de tratar o cadáver de um mouro como uma carcaça de animal, utilizada como objeto de exposição. Conforme descrito abaixo, os chamados rústicos, que seriam os cidadáos que habitavam os arredores de Tarcisis, mantinham o corpo do mouro coberto e só o mostravam àqueles que pagassem:

Os rústicos arrastavam os restos do mouro para que todos soubessem a notícia e os felicitassem e remunerassem condignamente pelo feito. Tencionavam continuar a exibi-lo, por todas as povoaçóes em redor, arrecadando como recompensa o dinheiro que a generosidade dos cidadãos quisesse despender. Como costumam fazer com as carcaças dos lobos ou dos ursos [...] (Carvalho, 1997: 143)

A animalização e coisificação dos mouros, presentes nas citaçóes acima, equiparam-se, de fato, à desumanização dos "muçulmanos" denunciada na obra de Primo Levi. Há, no entanto, um ponto fundamental que constitui uma inversão entre as duas constituiçóes narrativas. O relato memorial composto por Lúcio apresenta a visão de um cidadão romano, que tem como parâmetros apenas os referenciais desse Império, como as legióes romanas, por ele citadas. A desumanização dos mouros, nesse caso, é apresentada pelo discurso parcial do narrador que os percebe, principalmente, através da sua diferença em relação a um modelo muito específico de civilização. Já no caso da obra de Levi, o narrador é também um prisioneiro do Campo de Concentração e por isso a sua percepção desse outro, reificado, não se constitui por nenhum tipo de distanciamento cultural, mas justamente pela assustadora e terrível proximidade entre eles. E esse triz que separa o humano do que já não pode mais ser considerado um homem é que motiva grande parte das reflexóes apresentadas no texto. 
A possibilidade de se encontrar uma marca de humanidade, de dignidade ou de civilização é perseguida obsessivamente ao longo da narrativa. Mas, no contexto final da obra, apresenta-se a confissáo da experiência de completa animalização, vivenciada no Campo de Extermínio, desfazendo-se, assim, aquele tênue limite que separava a civilização da barbárie:

Jazíamos num mundo de mortos e de fantasmas. O último vestígio de civilização desaparecera ao redor e dentro de nós. A obra de embrutecimento empreendida pelos alemáes triunfantes tinha sido levada ao seu término pelos alemáes derrotados. É um homem quem mata, é um homem quem comete ou suporta injustiças; não é um homem que, perdida já toda reserva, compartilha a cama com um cadáver. Quem esperou que seu vizinho acabasse de morrer para tirar-lhe um pedaço de pão, está mais longe (embora sem culpa) do modelo do homem pensante do que o pigmeu mais primitivo ou o sádico mais atroz. Uma parte de nossa existência está na alma de quem se aproxima de nós; por isso, não é humana a experiência de quem viveu dias nos quais o homem foi apenas uma coisa ante os olhos de outro homem. (Levi, 1988: 173)

Nesta impressionante elaboraçáo, relativa ao reconhecimento da condição primitiva, bárbara e animalesca a que chegaram os prisioneiros, constitui-se uma conclusão ainda mais surpreendente, que pode ser melhor apreendida na junção dos seguintes fragmentos: "É um homem quem mata, é um homem quem comete ou suporta injustiças" e "[...] não é humana a experiência de quem viveu dias nos quais o homem foi apenas uma coisa ante os olhos de outro homem." (Levi, 1988: 173). Ou seja, a completa obra de barbarização humana, não se consuma nos atos de extrema violência sofridos ou praticados, mas na reificação do homem pelo homem. A incapacidade de reconhecimento da dimensão humana do outro é o que confere ao homem a verdadeira condição bárbara.

Esse pronunciamento assemelha-se com uma concepção de barbárie processada por Francis Wolff. Para superar a falaciosa definição maniqueísta de civilização e barbárie e a improdutiva relativização desses termos, Wolf elabora a seguinte proposição:

Chamaremos de bárbara toda cultura que náo disponha, em seu próprio cerne, de estruturas que lhe permitam admitir, assimilar ou 
reconhecer outra cultura - ou seja, a simples possibilidade de outra forma de humanidade. (Wolff, 2004: 41)

Assim, das elaboraçóes de Primo Levi e Wolf, aqui expostas, concluímos que a barbárie poderia se configurar pela incapacidade de reconhecimento e aceitação da alteridade. Mas, a apreciação de Lúcio e de seus concidadãos, concernente aos mouros, revela, exatamente, a impossibilidade de uma mínima compreensão de sua humanidade. E, se por um lado, a expectativa de uma elaboração, relativa à interação entre alteridades culturais, ou a própria terminologia aí empregada, parece totalmente anacrônica para o contexto histórico contemplado no romance de Mário de Carvalho, por outro, a forma como a narrativa de Levi é aludida parece provocar, de forma bem consciente, esse tipo de reflexão. E, realmente, os fatos referentes à presença dos mouros em Tarcisis são ínfimos, o que ganha destaque no texto é, justamente, a percepção dos cidadãos em relação aos invasores.

Ocorre que, embora a abordagem temporal de Um deus passeando pela brisa da tarde apresente uma rigorosa reconstituição histórica, fiel aos ideários da época, permite, entretanto, que uma precisa articulação dos fatos históricos resulte em estruturas, bastante originais, capazes de alcançar diretamente o período de enunciação do romance: final do século xx. Dessa forma, sem quebrar as expectativas internas de verossimilhança, o texto de Mário de Carvalho consegue comunicar-se com a nossa atualidade propondo, de forma sutil, reflexóes bastante perspicazes sobre assuntos complexos, como a questáo da alteridade.

É interessante pensar que o referido romance de Mário de Carvalho, publicado em 1994, e cujo tempo ficcional corresponde ao II século da Era Cristã, eleja, como parte de sua temática, a presença dos mouros na regiáo da Lusitânia. A peculiaridade da questão assenta-se sobre o fato de que nesse período, evidentemente, não existia, ainda, a religião muçulmana e, portanto, o conflito entre lusitanos e mouros não tinha o peso da motivação religiosa. E se, conforme apresentamos acima, há uma equalização desdenhosa dos estrangeiros, considerados como bárbaros, são apenas os mouros, aqueles que, de fato, são retratados na obra. Ou seja, se "o lado errado do Marenostro" é sempre o outro, o mouro poderia ser um representante dessa alteridade no imaginário português. Assim, poderíamos entrever, nessa obra de Mário de Carvalho, a sugestão de uma prevalência moura na cultura portuguesa que, para além dos fatos históricos e religiosos, alcançaria uma dimensão simbólica propícia para se designar o outro - bárbaro, invasor, exótico, diferente. 


\section{2 - A barbárie intrínseca à civilização romana}

Conforme colocado anteriormente, a presença do elemento mouro em Um deus passeando pela brisa da tarde possibilita outras reflexóes, também profícuas, sobre a questáo da barbárie. Nesse tópico, trataremos do assunto, partindo da seguinte situação: ao mesmo tempo em que a narrativa apresenta o cerco dos bárbaros mouros a uma província da Lusitânia sob o domínio romano, no ir século da Era Cristã, o narrador sugere a presença da barbárie no âmago, mesmo, desta sociedade. Decorre daí uma relativização do conceito de bárbaro como aquele que vem de fora: a barbárie, associada ao gosto pela violência, é reconhecida nas práticas cotidianas dos cidadáos romanos. Atentamos para a inusitada configuraçáo estabelecida na obra de Mário de Carvalho, que torna patente a disposição de representaçóes bárbaras no âmago de um Império que, ironicamente, se vangloriava por seu alto grau de civilidade.

Lúcio, ao insinuar, em sua narrativa, a presença da barbárie localizada no interior da civilização romana, não o faz seguindo o viés da alteridade, como foi discutido no tópico anterior, mas considerando, especificamente, as práticas violentas exibidas de forma espetacular para um público completamente embevecido. A seguir apresentamos um fragmento do texto memorial de Lúcio Quíncio, no qual se pode acompanhar a descrição das práticas selvagens ocorridas nas arenas de gladiadores:

O gladiador musculado que entrava de braços levantados, entre clamores, saía daí a minutos arrastado pelos pés, depois de o crânio lhe ter sido rebentado com um malho pelos oficiais da arena, travestidos de Caronte. Dentro em breve, nesta ou noutra hora, o mesmo aconteceria ao que o tinha derrubado. "Dá-lhe", "degola", berravam os lorários saltitando em volta dos combatentes de chicote em riste. Hiante, a populaça acompanhava em coro: “Derruba", "fere!". (Carvalho, 1997: 178-179)

O discurso de Lúcio, longe de reproduzir o tom de exortação manifestado pelos outros cidadáos romanos que assistiam ao evento, parece conter um vislumbre de assombro e indignação ante a violência dos acontecimentos por ele presenciados e narrados. De fato, se observarmos uma colocação anterior do protagonista, referente ao mesmo evento, percebemos uma atitude crítica bem sutil, revelada em uma interessante formulação, que sobrepóe o sentido de barbárie, simbolizado pelo sangue derramado nestes eventos violentos, à civilidade romana, presentificada pelos perfumes: 
Não sei se era impressão minha: parecia-me que, ao fim de algum tempo, o cheiro húmido, salgado, do sangue sobrelevava o odor dos perfumes preciosos que impregnavam a bancada em que nos sentávamos. (Carvalho, 1997: 177)

E, finalmente, no diálogo entre Lúcio e o imperador Marco Aurélio Antonino, o protagonista confessa a sua repugnância e incompreensão frente à carnificina praticada nas arenas. Mas, o imperador, admitindo que isso possa ser, de fato, considerado uma prática sacrificial humana, ressalta que, ainda assim, justifica-se como algo necessário para acalmar a ira do povo. O seguinte excerto apresenta o pronunciamento de Marco Aurélio dirigido a Lúcio, no qual fica evidente a defesa de uma "espetacularização da barbárie" para que se possa controlar a violência inerente à própria condição humana:

Olha que é falso que nós, Romanos, tenhamos acabado com os sacrifícios humanos. Apenas alteramos os procedimentos. O que proibimos aos povos submetidos são as suas formalidades peculiares de matar. E consideramo-los romanizados e felizes quando adotam os nossos ritos, que são estes. [...] Sabes? A sede de sangue é táo grande que, não podendo saciá-la nos anfiteatros, iriam saciá-la nas ruas. Se eu proibisse os espetáculos, voltaríamos talvez às guerras civis e às proscriçôes. Surgiriam outros césares. Devo correr esse risco? (Carvalho, 1997:186)

Assim, as camadas populares de Tarcisis ou de Roma, a quem Lúcio se refere, com desprezo, como turba ou populacha, são sustentadas pela prática do "panis et circenses", com ênfase à necessidade dos espetáculos violentos. Resulta, dessa conjuntura, uma forma de alienação popular astuciosamente aproveitada e promovida pelos governantes romanos. O tribuno Marco Agneio Scauro, representante do poder romano em Tarcisis, compartilha da visão da espetacularização da violência até mesmo nos procedimentos jurídicos, como o julgamento de Arsenna, um salteador capturado em Tarcisis, e dos seguidores fanáticos da nova religião, os cristãos. Em uma discussão com o duúnviro, na qual este recusa-se a aceitar a correspondência entre um julgamento e um espetáculo, Marco Scauro rebate:

Não achas? Não vai o povo assistir? Não se fazem apostas? Não há claques e entusiasmos? Não se comenta no fórum? Não é o assunto dominante de todas as especulaçóes? Não pode preceder um segundo 
acto, que é o dos suplícios e execuçóes? Náo exulta a plebe, de modo a ficar contente e grata? (Carvalho, 1997: 274)

A coerência dos argumentos de Scauro reflete, de fato, a estrutura alienante que predominava em todas as instâncias do Império. Verificamos, entáo, que as relaçóes entre barbárie e civilização, nesse contexto, alcançam uma configuração bastante complexa. A barbárie, associada ao sentido de violência, é compreendida como uma necessidade inerente à condição humana. Mas, para impedir que atos de selvageria comprometam as estruturas civilizacionais romanas, são promovidos espetáculos brutais, nos quais sacrifícios humanos são praticados, em um contexto esportivo de lutas e jogos. Dessa forma, a ferocidade dos cidadáos fica circunscrita aos circos e arenas de gladiadores.

Além do espaço específico, onde se promove uma barbárie controlada, várias manifestaçôes que pareçam comprometer os estatutos civilizacionais romanos - como o cristianismo, os mouros ou os bandidos - são juridicamente avaliadas, com todo o rigor das leis, para, então, serem eliminadas em sacrifícios festivos, também previstos nesses julgamentos. E, ordenando esse esquema de controle de criminalidade, através da prática circunscrita da violência, estão os governantes romanos, que, em posição bastante distanciada dos cidadãos comuns, não se comprazem desses espetáculos populares.

Assim, é o povo, de fato, que, alienado de sua capacidade de pensar, fazer escolhas, se revoltar, sendo, de certa forma, desumanizado, reproduz em sua relação com o outro, não-romano - o gladiador, o cristáo, o mouro - uma prática de reificação. É do interior dessa massa homogênea, cuja civilidade é extraída de práticas bárbaras, que se constitui a perspectiva desumanizada do outro e a incapacidade de reconhecimento e aceitação da alteridade.

E, nesse contexto, as tấo conhecidas palavras de Walter Benjamin tornam-se absolutamente precisas: "Nunca houve um monumento da cultura que não fosse também um monumento da barbárie." (Benjamin, 1985: 225). Nessa obra da literatura portuguesa contemporânea, pode-se confirmar a máxima elaborada pelo filósofo alemão, que destitui a convencional dicotomia "civilização e barbárie" e reconhece a presença da barbárie como estrutura intrínseca ao processo civilizatório. A aparente oposição entre a civilizaçáo romana e os invasores bárbaros é redimensionada, em Um deus passeando pela brisa da tarde, por uma estruturação narrativa, que evidencia, através da presença dos mouros, as práticas violentas e intolerantes necessárias para se obter o precário efeito de civilidade. 


\section{3 - Iunia Cantaber: a paixão traduzida como barbárie}

Já no início da narrativa, quando Lúcio encontra-se exilado e reflete sobre os problemas enfrentados, que teriam determinado sua condiçấo de desterrado, ele faz a seguinte colocação: "Ainda hoje olho com desconfiança quem venha do lado do Oceano. Mas será das praias que acorrem todos os perigos?" (Carvalho, 1997: 18). O perigo advindo do oceano são os mouros, mas uma condição fundamental para que Lúcio Valério perca sua posição de duúnviro e seja exilado de Tarcisis é o sentimento passional sentido por Iunia Cantaber, pois é isso o que compromete todas as decisóes públicas tomadas por ele. Assim, esse outro perigo insinuado na reflexão do protagonista-narrador seria, certamente, uma alusão à Iunia. Desde o princípio do romance define-se, dessa forma, um paralelismo entre a configuração ameaçadora dos mouros e aquela representada por Iunia Cantaber.

Tal perspectiva é reforçada também, em determinado ponto da narrativa, no qual a própria Iunia explicita sua identificação com os mouros. Isso ocorre no capítulo IX do romance, quando Lúcio surpreende Iunia Cantaber na intenção de enterrar um mouro, que seria apenas jogado em um lixo, e ela justifica sua atitude dizendo: "Este homem era meu irmão" (Carvalho, 1997: 147). A colocação de Iunia refere-se ao sentido cristão de irmandade entre os homens, mas funciona, ainda, como mais um indício da contiguidade entre o ataque dos mouros à Tarcisis e o sentimento avassalador que Iunia provoca em Lúcio Quíncio.

A angústia de Lúcio em relação à Iunia Cantaber é, de fato, bastante semelhante àquela experimentada quando ocorre a invasão dos mouros, e assenta-se, em ambos os casos, na incompreensão referente aos fatos inusitados e incontroláveis. Conforme apresentado no seguinte excerto, Lúcio Quíncio desenvolve um questionamento táo obsessivo quanto ineficaz acerca das motivaçóes dos mouros para agirem de forma, para ele, totalmente incoerente. Observa-se, ainda, em seu discurso, a crença um tanto pretensiosa de que o entendimento racional de tal situação poderia levá-lo ao seu controle e solução. Mas, utilizando os parâmetros civilizacionais romanos para refletir sobre a ação dos chamados bárbaros, Lúcio só pode perceber a desordem e incoerência da invasão moura:

Mas que deu àquela gente bisonha, mesquinha e bruta, para deixar, ululante, os seus desertos, [...] e vir desabar sobre a Lusitânia em correrias de sangue, talando fazendas, casas e gentes? Que ímpeto foi aquele que algum deus obscuro e ressaibado thes comunicou e que 
não perdoava madeira nem pedra, culpado nem inocente, livre nem escravo, e que trazia o único escopo de destruir e volver em deserto as cidades e os agros talentosamente erguidos por geraçóes que falam latim, cultuam os deuses e praticam o direito? Um exército conquistador pilha por turnos, poupa os vencidos, reconstrói as cidades, cobra o tributo, restabelece a ordem. [...] Mas, quando passa uma horda, deixa na terra a marca da pura irracionalidade, o restabelecimento do caos original [...] Por quê? Em nome de quê? Se tal eu soubesse, seria o mais sábio dos homens e poderia aconselhá-los com proveito. O por quê daquela ânsia dementada de destruir deve ser, de todos o mistério mais bem guardado. Não quis a divindade revelar-mo, apenas que lhe sofresse as conseqüências. (Carvalho, 1997: 16-17)

E, a persistente situaçáo de incômodo causada pelo sentimento inexplicável nutrido por Iunia causa, no protagonista, sensaçóes semelhantes a essas. A impossibilidade de comunicação com esse outro estranho, incompreensível, impenetrável, representado por Iunia Cantaber, revela-se, repetidamente, no discurso angustiado de Lúcio Quíncio, como se pode verificar nas seguintes colocaçôes: "Mas Iunia era um templo sem portas. Eu não conseguia descobrir nenhum acesso." (Carvalho, 1997: 163). Ou, um pouco adiante, em um trecho no qual se coloca o esvaziamento da própria humanidade de Iunia:

Impunha-se-me como que um obsidiante desafio de conseguir chegar a Iunia, à verdadeira Iunia, à humanidade de Iunia, por detrás daquele enleio espesso de frases e atitudes. [...] Ambos estávamos iludidos sobre a vulnerabilidade do outro. Ela, porque náo era pela sua piedade insólita que me tocava. Eu, porque sondava atrás das defesas de Iunia, onde, se calhar, não existia mais nada [...] (Carvalho, 1997: 166)

A incomunicabilidade entre Lúcio e Iunia parece mesmo estabelecer um distanciamento tão absoluto entre eles, quanto aquele apresentado pelo protagonista em relação aos mouros, como se pode depreender do seguinte fragmento:

E à alma de Iunia, seria possível aceder? Obter um sinal qualquer mesmo mínimo que significasse: olho-te, vejo-te, reconheço-te, compreendo-te? Eu não exigia mais que um momento em que as nossas palavras, em 
vez de se entrechocarem e enovelarem em linhas dispersas, eriçadas de asperezas, conseguissem convergir [...] (Carvalho, 1997: 170)

A aproximação entre o imperador-filósofo Marco Aurélio Antonino e Lúcio Quíncio, reveladora de uma perspectiva estóica, também presente no discurso do personagem-narrador, parece ser desconstituída à medida em que ele se deixa dominar pela intensa e inexplicável atração exercida por Iunia Cantaber. Os preceitos estoicistas ${ }^{1}$ de controle sobre as paixóes e de retidáo cívica e moral tornam-se incongruentes em relação às suas atitudes, pautadas, então, pelo desejo de se aproximar de Iunia e no intento de protegê-la da ira popular. O mundo civilizado, estóico e comedido de Lúcio é então invadido por um sentimento estranho, passional e excessivo.

Parece haver uma sobreposição de pontos de vista presentes ao texto de Lúcio, os quais refletem, às vezes de forma indissociável, o momento de rememoração dos fatos e o tempo pretérito em que eles foram vivenciados. Se algumas questôes relativas a sua atuação política e ao convívio com os outros magistrados puderam ser revistas de forma mais comedida e lógica, ao recordar os sentimentos experimentados por Iunia, entretanto, nota-se que a perspectiva do narrador permanece inalterada, imune a qualquer reflexão ordenadora. Além de não conseguir nomear, claramente, as sensaçóes arrebatadoras que lhe causara Iunia Cantaber, Lúcio apresenta, em sua elaboração memorial, uma atitude, ainda, perplexa e desconcertada.

Embora menos óbvio que os dois primeiros exemplos de barbárie, concernentes ao estrangeiro invasor e à violência romana, apontados anteriormente, a forma como Lúcio é afetado por Iunia e, ainda, a sua incompreensão frente a esse sentimento fazem com que o narrador a conceba como um elemento estranho, representativo de grande ameaça aos valores que lhe pareciam mais consistentes.

1 Lúcio, sendo contemporâneo de Marco Aurélio, pertenceria, cronologicamente, ao terceiro período do estoicismo romano, chamado estoicismo imperial ou novo estoicismo, representado, também, por Sêneca e Epicteto, entre outros. O item cinco, do livro V dos Pensamentos de Marco Aurélio, proporciona, de forma simplificada, uma noção geral dos aconselhamentos morais e regras de conduta representativos deste período da filosofia estóica: Faz-te a elas entáo, pois que dependem absolutamente de ti: sinceridade, gravidade, poder de agüentar, continência, aceitação do destino, moderação dos desejos, benevolência, liberdade, simplicidade, seriedade nos propósitos, grandeza de alma. (Marco Aurélio, 1971: 51) 
A contiguidade entre a maneira como o narrador autodiegético descreve sua interação com Iunia Cantaber e a barbárie em um contexto lato, advindo principalmente do sentido de alteridade estranha e ameaçadora, parece ter sido viabilizada, exatamente, pelas referências ao invasor mouro, contidas no discurso memorial de Lúcio. O modo como são pensados os mouros ou, mais precisamente, a dificuldade de apreensão desses povos, identificados como bárbaros, parece ter contaminado a estruturação narrativa e a percepção geral de Lúcio sobre toda a realidade a sua volta. Assim, de forma inconsciente, o narrador aparenta mimetizar, em suas preleçóes sobre Iunia Cantaber, as mesmas estruturas utilizadas para elaborar a relação de adversidade e alteridade referente aos mouros. 


\section{Bibliografia Geral}


(Página deixada propositadamente em branco) 


\section{Ediçôes de Mário de Carvalho}

(21990), Contos da sétima esfera. Lisboa, Caminho.

(1991), Quatrocentos mil sestércios. Lisboa, Caminho.

(71991), Casos do beco das sardinheiras, Lisboa, Caminho.

(31993), A Paixão do Conde de Fróis. Lisboa, Caminho.

(1996), Os Alferes. Lisboa, Caminho.

( $\left.{ }^{3} 1996\right)$, O livro grande de Tebas, Navio e Mariana. Lisboa, Caminho.

(1997), Um deus passeando pela brisa da tarde, Lisboa, Caminho.

$\left({ }^{3} 1997\right)$, Fabulário. Lisboa, Caminho.

(52003), Era bom se trocássemos umas ideias sobre o assunto. Lisboa, Caminho.

(32004), Fantasia para dois Coronéis e uma Piscina. Lisboa, Caminho.

('2006), A inaudita guerra da Avenida Gago Coutinho. Lisboa, Caminho.

(2008), A sala magenta. Lisboa. Caminho.

(2010), A Arte de Morrer Longe. Lisboa, Caminho.

\section{Estudos}

Adorno, T. W. ('1983), "Posição do narrador no romance contemporâneo". In: Benjamin, Honkheimer, Adorno, Habermas. Trad. port. José L. Grünnewald et alii. São Paulo, Abril Cultural: 269-273.

Albaladejo, T. (1986), Teoría de los mundos posibiles y macroestructura narrativa. Alicante, Universidade de Alicante.

Albaladejo, T. (1992), Semántica de la narración: la ficción realista. Madrid, Taurus.

Albérès, R. M. (1972), Métamorphoses du roman. Paris, Albin Michel.

Almeida, J. F. (1997), Bíblia Sagrada. Rio de Janeiro, Fecomex (Ed. Revisada e corrigida).

Alves, C. C. (2010) "Vestígios do trágico em Mário de Carvalho”. Navegaçôes 3. 1: 53-58.

Anacleto, M. T. (1996), “(Sub)versions du "cliché” romanesque au XVII siècle: le "roman bourgeois" de Furetière”, Confluências 14: 97-109.

Angelini, P. R. K. (2011) "Recensão de Carvalho, M. A arte de morrer longe. Lisboa, Caminho, 2010. 128p.”. Navegaçōes 4. 1: 131-133.

Arnaut, A. P. (2001), "Donas e donzelas n'a Demanda do Santo Graal”, Santa Barbara Portuguese Studies. Califórnia, n. 5: 29-71. 
Aristófanes (21989), A Paz. Tradução de Silva. M. F. Coimbra, Instituto Nacional de Investigação Científica.

Aristófanes (2006), As Aves. Tradução de Silva, M. F. Lisboa, Edições 70.

Aristóteles (1986), Poética. Tradução de E. Sousa. Lisboa, Fundação Gulbenkian.

Arnaut, A. P. (2002), Post-Modernismo no romance português contemporâneo. Fios de Ariadnemáscaras de Proteu. Coimbra, Almedina.

Assis, A. K. T. (2008), Arquimedes, o centro de gravidade e a lei da alavanca. Montreal, Apeiron Montral.

Auerbach, E (1976), Mimesis (A representação da realidade na literatura ocidental). São Paulo, Perspetiva [1 $1^{\text {a }}$ ed., 1946].

Aurélio, Marco (1971), Pensamentos. Versão de João Maia. Lisboa, Editorial Verbo.

Bakhtine, M. (1970), La Poétique de Dostoievsky. Paris, Éd. du Seuil.

Bakhtine, M. (1981), Dialogic imagination: four essays. Austin, University of Texas Press.

Bakthine, M. (1981), Problemas da poética de Dostoievski. Trad. port. Paulo Bezerra. Rio de Janeiro, Ed. Forense-Universitária.

Benjamin, W. (1985), "Sobre o conceito de História. Tradução de Sérgio Paulo Rouanet”. In: Obras escolhidas. Magia e técnica, arte e política. São Paulo, Editora Brasiliense: 222-232.

Bessière, J. (2010), Le roman contemporain ou la problemacité du monde. Paris, PUF.

Beye, C. R. (1964), "Homeric battle narrative and catalogues", Harvard Studies in Classical Philology 68: 345-373.

Bergson, H. (2001), O riso: ensaio sobre a significação da comicidade. Trad. port. Ivone C. Benedetti. São Paulo, Martins Fontes.

Bhabha, H. K. (1998), O local da cultura. Belo Horizonte, Editora UFMG.

Bianchet, S. B. (2004), Petrônio. Satyricon. Edição bilíngüe. Belo Horizonte, Crisálida.

Bougnoux, D. (1991), "Le principe d'identification”. In Personnage et Histoire Littéraire. Toulouse, Presses Universitaires du Mirail: 187-195.

Brandão, J. L. (2001), A poética do Hipocentauro: Literatura, sociedade e discurso ficcional em Luciano de Samósata. Belo Horizonte, Ed. UFMG.

Brasete, M. F. (2003), “A crítica às mulheres no fr. 7 de Semónides de Amorgos”. In: Mora, C. M. (ed.), Sátira, Paródia e Caricatura: da Antiguidade aos nossos dias. Aveiro, Universidade de Aveiro: 39-56.

Brauner, E. F. (2009), “" Era bom que trocássemos umas ideias sobre o assunto”: ironia de um narrador e discussão do romance", Revista Electrónica de critica e teoria de literaturas. Dossiê: o romance português e o mundo contemporâneo 5. 2. Porto Alegre: 1-9.

Buescu, H. (1995), A Lua, a Literatura e o Mundo. Lisboa, Cosmos. 
Buescu, M. L. C. (1979), Aspectos da herança clássica na cultura portuguesa. Lisboa, Instituto de Cultura Portuguesa.

Camôes, L. (1979), Os Lusíadas. Prefácio de Hernâni Cidade. São Paulo, Abril Cultural.

Carcopino, J. (1993), La vida cotidiana en Roma en el apogeo del imperio, trad. esp. Madrid, Ediciones Temas de Hoy.

Cardoso Bernardes, J. A. (1988), O Bucolismo Português. A égloga do Renascimento e do maneirismo. Coimbra, Livraria Almedina.

Carvalho, M., (2003), "Mário de Carvalho: crónica do aturdimento". JL - Jornal de Letras, Artes e Ideias 864, 12/11: 12.

Ceia, C. (2007), A Construção do romance (Ensaios de literatura comparada no campo dos estudos anglo-portugueses). Coimbra, Almedina.

Chevalier, J., Gheerbrant, A. (1994), Dicionário dos Símbolos, trad. port., Lisboa, Editorial Teorema.

Colaço, J. (1995), “Mário de Carvalho”, Biblos. Enciclopédia verbo, I, s.u.

Compagnon, A. (2001), O demônio da teoria: Literatura e senso comum. Belo Horizonte, Editora UFMG.

Constâncio, N. (2007), Ruinas e incertezas em "Um Deus passeando pela brisa da tarde”, de Mário de Carvalho. Lisboa, Edições Colibri.

Costa, L. S. (1995), “Era Bom que Trocássemos Umas Ideias Sobre O Assunto, de Mário de Carvalho. A Arquitectura, A Violência”. In: Público/Leituras, 11 de Novembro:10.

Cotrim, J. P. (1996), Entrevista a Mário de Carvalho: "Alguma coisa me perturba”. Ler/Livros e Leitores 34: 45.

Cotrim, J.P. (1996), "Mário de Carvalho. O Mistério da Literatura”, entrevista ao autor. LER 34, Primavera.

Cristóbal, V. (1992), "Búsqueda de campo, hastío de ciudad. Pasión antigua y contemporánea”. In: Guzmán, A. et alii (ed.), Aspectos modernos de la Antigüedad y su aprovechamiento didáctico. Madrid, Ediciones Clásicas: 131-143.

Davison, M. (1976), "The thematic use of ekphrasis in the ancient novel”, in Erotica antiqua. Acta of the International Conference on the Ancient Novel. Bangor, ICAN: 32-33.

Devereux, G. (1975), Dreams in Greek tragedy. Oxford, Basil Blackwell.

Dijksterhuis, E. J. (1987), Archimedes. Translated by C. Dikshoorn. Princeton University Press.

Diogo, A. A. L. (1997), "Exórdio". In: Biblos- Enciclopédia Verbo das Literaturas de Lingua Portuguesa. Lisboa, São Paulo, Verbo.

D’Onofrio, S. (1978), Poema e Narrativa: estruturas. São Paulo, Duas Cidades. 
Duncan, T.S. (1935), “The deus ex machina in Greek Tragedy”. Philological Quarterly 14: $126-141$.

Dunn, F. M. (1985), Euripidian Endings: a Study of the Choral Exit, the Action, the Concluding Prophecy and the Deus ex Machina. Yale University: 111-167.

Eco, U. (1979), Leitura do Texto Literário. Lector in Fabula. Trad. Mário Brito. Lisboa, Presença.

Entrevista com Mário de Carvalho http://www.homemmag.pt/pt/index.php/arte-e-literatura/arquivo-arte-literatura/87-luisa-costa-gomes-entrevista-mario-de-carvalho

Ernout, A. ( $\left.{ }^{11} 1993\right)$, Pétrone. Le Satyricon. Paris, Les Belles Lettres.

Ernout A, Meillet, A. ( $\left.{ }^{4} 1967\right)$, Dictionnaire etymologique de la langue latine: histoire des mots. Paris, Librairie C. Klincksieck.

Errandonea, I. (1954), Diccionario del mundo clásico. Barcelona, Editorial Labor.

Eschilo ( $\left.{ }^{4} 2000\right)$ I sette contro Tebe. Con testo a fronte. Introd. Umberto Albini. Trad. Ezio Savino. Milano, Garzanti Editore.

Feijóo, B. (1998), Um Não Sei Quê. Lisboa, Vega [1746].

Ferreira, C. (2003), “Mário de Carvalho. A arte de bem iludir o leitor”. In: Rodapé: 45-51.

Ferreira, P. S. (1999), “A paródia e as suas implicações didácticas”. In: Torrão, J. M. N. (ed.), III Colóquio Clássico - Actas. Aveiro, Universidade de Aveiro: 113-137.

Ferreira, P. S. (2000), Os elementos paródicos no Satyricon de Petrónio e o seu significado. Lisboa, Colibri.

Ferreira, P. S. (2003), “Paródia ou paródias?”. In: Mora, C. M. (ed.), Sátira, Paródia e caricatura: da Antiguidade aos nossos dias. Aveiro, Universidade de Aveiro: 279-300.

Fialho, M. C. (1992), Luz e trevas no teatro de Sófocles. Coimbra, Instituto Nacional de Investigação Científica.

Figueiredo, M. N. (2006), "Com humana crueldade se tece um conto. A propósito de Homenagem ao Papagaio Verde”. In: Santos, G. (ed.) Jorge de Sena: Ressonâncias e Cinqüenta Poemas. Rio de Janeiro, 7Letras.

Fowler, D. P. ((1991), "Narrate and describe: the problem of ecphrasis", Journal of Rhetorical Studies 81: 25-35.

Frow, J. (1986), “Spectacle Binding: On Character”. Poetics Today 7. 2: 227-250.

Gaffiot, F. (1934), Dictionnarie Illustré Latin-Français. Paris, Librairie Hachette.

Garrett, A. (1973), Viagens na minha Terra. Rio de Janeiro, Editora Três.

Genette, G. (1972), Figures III. Paris, Ed. du Seuil.

Gennete, G. (1997), L'Cuvre de l'Art. La Relation Esthétique, II. Paris, Ed. du Seuil.

Genette, G. (2004), Métalepse. Paris, Ed. du Seuil.

Gomes da Torre, M. (1992), “Acerca da tradução da metáfora”. Linguas e Literaturas 9: 209-226. 
Grimal, P. (s/d), Dicionário de Mitologia Grega e Romana. Lisboa.

Guillén, J. (1977), Vrbs Roma - vida e costumbres de los romanos, vol. I: La vida privada. Salamanca, Ediciones Sígueme.

Guthrie, W. K. C. (1976), Les Sophistes. Paris, Payot.

Halliwell, S. (1968), Aristotle's Poetics. Chicago and London.

Hamon, P. (1976), “O que é a descrição?”. In: Seixo, M. A. (ed.), Categorias da narrativa. Lisboa, Arcádia: 61-83.

Hardwick, L. (2003), Reception Studies. Greece and Rome. New Surveys in the Classics. Oxford, Oxford University Press. [recensão do livro por Martin M. Winkler, in Bryan Mawr Classical Review 2004].

Heródoto. (2002), Histórias. Livro I. Tradução de Ferreira, J. R., Silva, M. F. Lisboa, Ediçóes 70. Heródoto (1997), Histórias. Livro III. Tradução de Silva, M. F., Abranches, C. Lisboa, Ediçóes 70. Heródoto (2000), Abranches, C., Histórias. Livro IV. Tradução de Silva, M. F., Abranches, Lisboa, Edições 70.

Homero (2003), Odisseia. Tradução de Frederico Lourenço. Lisboa, Livros Cotovia.

Homero (2005), Ilíada. Tradução de Frederico Lourenço. Lisboa, Livros Cotovia.

Hoorn, J. F., and Konijn, E. A. (2003), "Perceiving and experiencing fictional characters: An integrative account”. Japanese Psychological Research 45. 4: 250-268.

Horácio (1975), Arte Poética. Tradução de R. M. R. Fernandes. Lisboa, Clássica Editora.

Hutcheon, L. (1977), “Modes et formes du narcisisme littéraire”. Poétique 29: 90-106.

Hutcheon, L. (1984), Narcissistic Narrative. The Metafictional Paradox. New York and London, Methuen.

Hutcheon, L. (1985), A Theory of Parody. The Teachings of Twentieth Century Art Forms. New York \& London, Methuen; (1989), Uma teoria da paródia, trad. port. Lisboa, Ediçóes 70.

Hutcheon, L. (1988), A poetics of Postmodernism. History, Theory, Fiction. New York/London, Routledge; (1991), Poética do Pós-Modernismo. Trad. Ricardo Cruz. Rio de Janeiro, Imago.

Hutcheon, L. (2000), Teoria e Política da Ironia. Trad. port. Julio Jeha. Belo Horizonte, Editora UFMG.

Immerwahr, H. R. (1966), Form and thought in Herodotus. University of North Carolina.

Izaac, H. J. ( ${ }^{3} 1969$, 1973), Martial. Épigrammes, I-II. Paris, Les Belles Lettres.

Jauss, H. R. (1986), Experiencia y Hermeneutica Literaria. Ensayos en el campo de la experiencia estétca. Madrid, Taurus, [1977].

Jenny, L. (1979), "A estratégia da forma”, Poétique. Revista de teoria e análise literárias. Trad. port. Clara C. Rocha. Coimbra, Almedina: 5- 49. 
Jerome, K. J. , “Three men on the Brummel'. In: http://www.gutenberg.org/catalog/world/ readfilefk_files $=2061881$

Jourdan, P. (1996), "Paul Valéry chasseur de perroquets", Confluências 14: 51-59.

Júdice, N. (1997), Viagem por um século de Literatura Portuguesa. Lisboa, Relógio d'Água.

Julien, Y. (1998), Aule-Gelle. Les nuits attiques, IV. Paris, Les Belles Lettres.

Jurado, F. G. (1999), "Apuntes para una historia prohibida de la literatura latina en el siglo XX: La voz de los lectores no académicos”. In: Morán, M. C. A.; Iglesias Montiel, R. M. (eds.), Contemporaneidad de los clásicos en el umbral deI tercer milenio. Actas deI Congreso Internacional Contemporaneidad de los clásicos: La tradición greco-latina ante el siglo XXI. La Habana, Universidad de Murcia: 77-85.

Kerferd, G. B. (2003), O movimento sofista. Trad. port. Margarida Oliva. São Paulo, Ediçôes Loyola.

Kirk, D. M. (1960), The digression, its use in prose fiction from the Greek romance through the eighteenth century. Stanford University.

Kristeva, J. (1974ª), Introdução à semanálise. São Paulo, Perspectiva.

Kuester, M. (1992), Framing Truths - Parodic Structures in Contemporary English-Canadian Historical Novels. Toronto/London, Toronto University Press.

Lausberg, H. (1963), Elementos de retórica literária. Trad. port. Raul M. Rosado Fernandes, Lisboa, Gulbenkian.

Leão, D. F. (1996), “Trimalquião: a humanitas de um novo-rico”. Humanitas 48: 161-182.

Leão, D. F. (1997), “Trimalquião à luz dos Caracteres de Teofrasto”. Humanitas 49: 147-167.

Leão, D. F. (1998), As Ironias da Fortuna. Sátira e Moralidade no Satyricon de Petrónio. Lisboa, Colibri.

Leão, D. F. (2004), “Zoilo e Trimalquião, duas variaçôes sobre o tema do novo-rico”. Humanitas 56: 191-208.

Leão, D. F. (2004a), “O Satyricon de Petrónio e a crise dos paradigmas tradicionais”. In: Nascimento, A. (ed.), Antiguidade Clássica: Que fazer com este património?. Lisboa, Centro de Estudos Clássicos: 233-242.

Leão, D. F. (2005), Petrónio. Satyricon. Lisboa, Cotovia.

Lepaludier, L (2002), Métatextualité et métafiction. Théorie et analyses, Presses Universitaires de Rennes, CRILA.

Levi, P. (1988), É isto um homem? Rio de Janeiro, Rocco.

Lévy, E. (1983), "Le théâtre et le rêve: le rêve dans le théâtre d'Eschyle", in Zehnacker, H. (ed.), Théatre et spectacles dans l'Antiquité. Actes du Colloque de Strasbourg. Leiden: 141-168.

Lopes, S. R. (2003), Literatura, Defesa do atrito. Lisboa, Copiart. 
Lourenço, E. ('1982), "Da literatura como interpretação de Portugal”. In O Labirinto da Saudade (Psicanálise Mitica do Destino Português). Lisboa, D. Quixote: 85-126.

Lourenço, F. (2003), Homero. Odisseia. Lisboa, Cotovia.

Luciano (1996), Uma história verídica. Tradução de C. Magueijo. Lisboa, Editorial Inquérito Limitada.

Lukács, G. (1989), Théorie du roman. Paris, Flammarion [1916].

"Na Lusitânia com Mário de Carvalho (História, paródia e ironia em Quatrocentos mil sestércios e Um deus passeando pela brisa da tarde)". In Veredas 5 (2002) 211-224.

Macedo, A. G. (2008), Narrando o pós-moderno: reescritas, revisôes, adaptaçôes. Braga Universidade do Minho.

Machado, J. P. (1995), Dicionário etimológico da Língua Portuguesa. Lisboa, Livros Horizonte.

Malina D. (2002), Breaking the frame: metalepsis and the construction of the subject. Columbus, Ohio State UP.

Margolin, U. (2005), “Character”. In: Herman, D., Jahn M., Ryan, M.-L. (eds.), Routledge Enciclopedia of Narrative Theory. London/New York, Routledge: 54-57.

Marinho, M. F. (1996), "O sentido da história em Mário de Carvalho", Revista da Faculdade de Letras. Linguas e Literaturas: 257-267.

Marinho, M. F. (2010), "À la recheche de l'identité perdue. Essai sur la crise d'identité dans le roman portugais contemporain”. In: Besse, M. G. \& Ralle, M. (eds.), Les Grands Récits: Miroirs Brisés? Paris, Índigo:186-198.

Martin, F. (1987), Les mots latins. Paris, Hachette.

Martins, J. C. O. (2011), "Mário de Carvalho e a reflexão metaficcional sobre o futuro do romance”. Diacrítica. Dossiê Literatura e Religiāo 25/3: 23-44.

Martins, J. C. O. (2011), “Pensar Portugal - ironia, paródia e desencanto: Mário de Cavalho e o retrato melancólico de um país". In: Carvalho da Silva, J. A., Martins, J. C. O., Gonçalves, M. (eds.), Pensar a Literatura no Séc. XXI. Braga, Univ. Católica Portuguesa: 463-478.

Martins, J. C. O. (s.d.), "La barbarie de l'ignorance dans la culture postmoderne et la fiction de Mário de Carvalho". In: De l'Extrême: pratiques du contemporain dans les mondes ibériques et ibéro-américains, Paris, CRIMIC [em publicação].

Martins, M. F. (1983), Sombras e transparências da literature. Lisboa, INCM.

Martins, Maria João (2003), "Mário de Carvalho: crónica de um aturdimento" [entrevista], JL - Jornal de Letras, Artes e Ideias, no 864, 12 novembro, p. 12.

Mead, G. (1990), “The Representation of Fictional Character”. Style 24. 3: 440.

Medeiros, W. (1997), "Do desencanto à alegria: o Satyricon de Petrónio e o Satyricon de Fellini”. Humanitas 49: 169-175. 
Melanda, P. C. O. (2001), Pela mão de Clio. A reescrita da História em Mário de Carvalho. Aveiro. 38. Dissertação de Mestrado em Estudos Portugueses, apresentada à Universidade de Aveiro. Exemplar em CDRom.

Melero Bellido, A. (2001), "La utopia cómica o los límites de la democracia”, Cuadernos de Literatura Griega y Latina 3: 7-25.

Melero Bellido, A. (2004), "La lengua de la utopia". In: López Eire, A., Guerrera, A. R. (Eds.). Registros Lingüísticos en las lenguas clásicas. Salamanca, Ediciones Universidad Salamanca: 149-172.

Mendes, A. M. G. (1999), "Cultura clássica em Um Deus Passeando pela brisa da tarde de Mário de Carvalho”, III Colóquio Clássico - Actas, Aveiro: 347-363.

Mendes, A. M. G. (2005), “Trimalquião, os coronéis e a piscina: retrato impiedoso de um país em crise”. Ágora. Estudos Clássicos em Debate. Aveiro 7: 129-150.

Mendes, J. P. (1997), Construção e Arte das Bucólicas de Virgílio. Coimbra, Almedina.

Mendonça, F. (1997), “A Paixão do Conde Fróis”. Colóquio/Letras 99. Setembro-Outubro.

Mexia, P. (2005), “O Manuel Germano”. Diário de Notícias. Artes, 17 de Junho: http:// dn.sapo.pt/2005/06/17/artes/o_manuel_germano.html

Moisés, M. ('1973), A criação literária: introdução à Problemática da Literatura. São Paulo, Melhoramentos.

Mora, C. M. (2003), “A outra resposta de Tirésias”. In: Mora, C. M. (ed.), Sátira, Paródia e caricatura: da Antiguidade aos nossos dias. Aveiro, Universidade de Aveiro: 7-13.

Morais e Silva, A. (1953), Grande Dicionário da Lingua Portuguesa. Lisboa, Confluência.

Mourão, J. A. (1998), "Posfácio”, a Feijóo, Benito - Um Não Sei Quê. Lisboa, Vega.

Nickel, R. (1999), “Lucian's True Story: impressions of a fancy voyage”, Euphrosyne 27: 249-257.

Niederauer, S. (2008), "Era bom que trocássemos umas ideias sobre o assunto ou $\mathrm{O}$ simulacro da narrativa na pós-modernidade”. Letras de Hoje 43. 4: 83-88.

Oliveira, B. S. (1997), Eurípides. Hipólito. Brasília, Editora UNB.

Onelley, G. B. (2004), “A resistência da nau: cidade na luta pelo poder”. Calíope 12: 33-42.

Otte, G. (1996), "Rememoração e citação em Walter Benjamin". Revista de Estudos de Literatura 4. Belo Horizonte, Centro de Estudos Literários (CEL), Faculdade de Letras da UFMG: 211-223.

Pereira, E. (2003), "Viagens na minha terra: ciladas da representação". Revista do Centro de Estudos Portugueses 23 n. 32: 61-68.

Pereira, S. M. (2008), “Poética dos sonhos e das visōes em estado de vigília - I”, Humanitas 60: 11-28.

Pereira, S. M. (2009), "Poética dos sonhos e das visōes em estado de vigília - II”, Humanitas 61: 5-18.

Perelman, C. O. (1993), O Império Retórico: Retórica e Argumentação. Tradução de Fernando Trindade e Rui Alexandre Grácio. Porto, Ediçóes Asa. 
Perrin-Naffakh. A.-M. (1996), "Le langage cliché: aveu d'usure ou pouvoir d'écho". Confluências 14: 7-14.

Perrone-Moisés, L. (1979), “A intertextualidade crítica”. Poétique. Revista de teoria e análise literárias. Trad. port. Clara C. Rocha. Coimbra, Almedina: 209-230.

Pimentel, C. S. (2001), "O latim nas literaturas portuguesa e francesa: instrumentos, métodos e agentes de ensino”, Ágora, Estudos Clássicos em Debate 3: 183-185.

Piwnik, M.-H. (1998), "Mário de Carvalho: crónica de um desfecho anunciado", Veredas 1, Porto: 317-325.

Piwnik, M.-H. (2004), “De Sienkiewicz a Mário de Carvalho: Duas construções da História”. In: Literatura e História. Actas do Colóquio Internacional, Porto, vol. II: 139-144.

Platão ( $\left.{ }^{12} 2010\right)$, República. Trad. Maria Helena da Rocha Pereira. Lisboa, Fundação Calouste Gulbenkian.

Préchac, F. (1987), Sénèque. Lettres a Lucilius, II. Paris, Les Belles Lettres.

Queirós, E. de (s./d.), Os Maias. Lisboa, Livros do Brasil.

Queirós, E. de (2000), O Crime do Padre Amaro. Ed. crítica de Carlos Reis e M. Rosário Cunha. Lisboa, IN-CM.

Rabaté, E. (1996), "Henri Michaux et le cliché: résistance et fascination”. Confluências 14: 61-75.

Raimond, M. (1989), Le Roman. Paris, Armand Colin.

Reis, C. (1996), "Mário de Carvalho. Incitação ao romance”. Jornal de Letras 28 Agosto: 22-23.

Reis, C. (1997), "Fábula”. In: Biblos-Enciclopédia Verbo das Literaturas de Lingua Portuguesa. Lisboa, São Paulo, Verbo: 462-463.

Reis, C. (2005), História crítica da literatura portuguesa, vol. IX (Do neorrealismo ao postmodernismo). Lisboa, Verbo: 287-318.

Reis, C., Macário Lopes, A. C. (72007), Dicionário de narratologia. Coimbra, Almedina.

Ricoeur, P. (1983), Temps et Récit. T.I. Paris, Ed. du Seuil.

Rio Torto, G. M. (1996), "Linguagem e clichê", Confluências 14: 159-175.

Robilliard, M.-A. (2002), Água em pena de pato de Mário de Carvalho. Um teatro do desencanto. Trad. port. Manuel Ruas. Lisboa, Editorial Caminho.

Rocha Pereira, M. H. (1955), Concepçōes Helénicas de felicidade no além: de Homero a Platão. Coimbra, Maranus.

Rocha Pereira, M. H. (1980), Poesia Grega Arcaica. Coimbra, Instituto de Estudos Clássicos.

Rocha Pereira, M. H. (1984), Estudos de História da Cultura Clássica, vol. II (Cultura Romana). Lisboa, Fundação Calouste Gulbenkian.

Rocha Pereira, M. H. ('1994), Romana - Antologia da Cultura Latina. Coimbra, Universidade de Coimbra. 
Rocha Pereira, M. H. ( $\left.{ }^{10} 2006\right)$, História da Cultura Clássica, I (Cultura Grega). Lisboa, Fundação Calouste Gulbenkian.

Rodrigues, L. G. (2005), “A Radioestesia”. In http://rprecision.logspot.com/2005/06/radiestesia.html Rose, M. A. (1979), Parody and meta-fiction. London, Croom Helm.

Sant'Anna, A. R. ('1985), Parodia, paráfrase \& cia. São Paulo, Ática.

Santos, R. B. (2009), Aspectos da Herança Clássica em Mário de Carvalho. Belo Horizonte, Faculdade de Letras da UFMG, 2009. [versão policopiada].

Saramago, J. (1989), História do Cerco de Lisboa. Lisboa, Caminho.

Saramago, J. (1990), "História e Ficção”. Jornal de Letras, Artes e Ideias, 6 de Março.

Schaeffer, J. M. (1992), L'art de l'àge moderne. L'esthétique et la philosophie de l'art du XVIIIème siècle à nos jours. Paris, Gallimard.

Schmidt, W. (1963), Der Deus Ex Machina bei Euripides. Tübingen University.

Schwartz, J. (1981), Murilo Rubião: A poética do Uroboro. São Paulo, Editora Ática.

Scodel, R. (1999), Credible impossibilities. Conventions and strategies of verisimilitude in Homer and Greek tragedy. University of Michigan Press.

Sedlmayer, S., "Sinais de fogo, aviso de incêndio: ideias estéticas, históricas e literárias em Jorge de Sena e Walter Benjamin”. In: Revista Literatrua e Autoritarismo. Dossiê Walter Benjamin e a Literatura brasileira. Santa Maria, Universidade Federal de Santa Maria/ RS. Disponível em http://w3.ufsm.br/grpesqla/revista/dossie05/art_02.php

Seel, M. (1992), "Le langage de l'art est muet". In: Bouchindhomme, Ch., Rochlitz, R. (eds.), L'art Sans Compas. Redéfinitions de l'Esthétique. Paris, Éd. du Cerf.

Segurado e Campos, J. A. (1991), Cartas a Lucílio, Lisboa, Fundação Calouste Gulbenkian.

Seixo, M. A. (1995), "Mário de Carvalho. Romance, Humanismo e BD”, JL - Jornal de Letras, Artes e Ideias, 12. 4: 24-25.

Sena, J. http://www.letras.ufrj.br/lerjorgedesena/port/antologia/ficcao-e-teatro/texto.php?id=319

Sequeira, M. G. R. (1996), Aproximação a uma Leitura do Risivel em A Paixão do Conde de Fróis. Tese de Mestrado apresentada à Faculdade de Letras da Universidade do Porto (dact.).

Settis, S. (2006), El futuro de lo 'clásico'. Traducción de Andrés Soria Olmedo. Madrid, Abada Editores.

Silva, M. F. (1987), Critica do teatro na comédia antiga. Coimbra, INIC.

Silva, M. F. (2005), Ensaios sobre Euripides. Lisboa, Cotovia.

Silva, M. F. (2007), "A porta na comédia de Aristófanes: uma entrada para a utopia”. In: Ensaios sobre Aristófanes. Lisboa, Cotovia: 257-274. 
Silva, M. F. (2008), "Mensagens, cartas e livros no teatro grego antigo", in Matos, M. C. (ed.), Helénicos. Estudos em homenagem do Prof. Jean-Pierre Vernant (1914-2007). Lisboa, Ediçôes Távola Redonda: 227-260.

Silva, M. F. (2009), Utopias e distopias. Coimbra, Imprensa da Universidade.

Silvestre, O. M. (1998), "Mário de Carvalho: Revolução e Contra-revolução ou um passo atrás e dois à frente”. Colóquio/Letras 147/148: 209-229.

Silvestre, O. e Diogo, A. L. (1998), "Entrevista a Mário de Carvalho", in <http://www. ciberkiosk.pt>, arquivo, $\mathrm{n}^{\circ} 1$ (15 pp.).

Simões, M. J. (2006), “Atrevidas e desbordantes: as personagens em Mário de Carvalho”. In Figuras da Fiç̧ão. Coimbra, Centro de Literatura Portuguesa: 79-92.

Spivak, G. Ch. ('2003), “Can the subaltern speak?” In: Asheroft, B., Griffith, G., Tiffin, H. (eds.), The post-colonial studies reader. New York, Routledge.

Spivak, G. Ch. (1998), "Puede hablar elsujeto subalterno?”. Orbis Tertius 3. 6: 1-44.

Sterne, L. (1860), The Works of Lawrence Sterne. London, Henry Bohn.

Thomasson, A. (2003), "Fictional Characters and Literary Practices". British Journal of Aesthetics 43. 2, April:138-157.

Todorov, T. (1999), O homem desenraizado. Trad. Christina Cabo. Rio de Janeiro, Record.

Torrão, J. M. N. (ed.) (1999), III Colóquio Clássico. Aveiro, Universidade de Aveiro.

Tosi, R. (2000), Dizionario delle sentenze latine e greche. Milano, Biblioteca Universale Rizzoli.

Trindade, L. (2004), “Os excessos de Abril”, História 65: 20-31.

Valente, A. M. (2004), Aristóteles. Poética. Lisboa, Gulbenkian.

Várzeas, M. (2001), Silêncios no teatro de Sófocles, Lisboa, Cosmos.

Villeneuve, F. (1970), Horace. Odes et Epodes, I. Paris, Les Belles Lettres.

Xavier, L. G. (2007), O discurso da ironia. Lisboa, Novo Imbondeiro.

Walton, K. (1990), Mimesis as Make-Believe: On the Foundations of the Representational Arts. Cambridge Mass., Havard University Press.

Waugh, P. (2003), Metafiction. The Theory and Practice of Self-Conscious Fiction. London \& New York, Routledge [1984].

Wesseling, E. (1991), Writing History as a Prophet. Postmodernist Innovations of the Historical Novel. Amsterdam/Philadelphia, John Benjamins.

Wolff, F. (2004), “Quem é bárbaro?”. In: Novaes, A. (ed.), Civilização e Bárbarie. São Paulo, Companhia das Letras: 19-43.

Woods, J. (1974), The Logic of Fiction. Paris, Mouton; (2010), A Mecânica da fiç̧âo. Lisboa: Quetzal. Zagajewski, A. (2003), En la belleza ajena, trad. esp. A. E. Diaz-Pintado Hilario, Valencia, Pre-Textos. 